\title{
Distribuição de Renda e Pobreza na Floresta Amazônica: Um Estudo a partir da Reserva Extrativista (RESEX) Chico Mendes
}

\author{
Income Distribution and Poverty in the Amazon Forest: A Study From the \\ Extractive Reservation Chico Mendes
}

\author{
Raimundo Claudio Gomes Maciel ${ }^{1}$ \\ Pedro Gilberto Cavalcante Filho ${ }^{2}$ \\ Elyson Ferreira Souza ${ }^{3}$
}

\begin{abstract}
Resumo: O processo de ocupação da Amazônia levou à desarticulação do extrativismo tradicional na região, tendo como um dos principais resultados os conflitos sociais e a luta pela posse da terra. As Reservas Extrativistas (RESEX) surgem para a resolução dos conflitos, buscando-se gerar trabalho e renda aos extrativistas, além de conservar o meio ambiente florestal. O objetivo deste trabalho é avaliar a geração e distribuição de renda na RESEX Chico Mendes, Acre, tendo em vista a discussão em torno da pobreza. A metodologia utilizada faz parte do projeto ASPF, desenvolvido na Universidade Federal do Acre, que trabalhou indicadores de resultados econômicos adequados à produção familiar rural da região, bem como indicadores de concentração de renda (Índice de Gini), além da linha de pobreza. Os resultados encontrados indicam desempenho econômico insuficiente para a reprodução das famílias, melhora na distribuição de renda e, consequente, redução da pobreza, além da ausência de miseráveis no seio da floresta.
\end{abstract}

Palavras-chaves: Desigualdade de Renda, Pobreza, Reserva Extrativista Chico Mendes, Amazônia.

Abstract: The process of occupation of the Amazon has led to the disarticulation of the traditional extractivism in the region, having as one of the main results of the social conflicts and the struggle for land. The extractive reserves (RESEX) appear to conflict resolution, seeking to generate jobs and income for extraction, and environmental conservation forest. The aim of this study is to evaluate the generation and distribution of income in the Chico Mendes Extractive Reserve, Acre, in view of the discussion on poverty. The methodology is part of the ASPF project, developed at the Federal University of Acre, who worked economic performance indicators appropriate to the rural family production in the region, as well as indicators of income concentration (Gini coefficient), and the poverty line. The results indicate insufficient economic performance for the reproduction of families, improvement in income distribution and, consequently, poverty reduction and the absence of miserable within the forest.

Key Words: Income Inequality. Poverty. Chico Mendes Extractive Reserve. Amazon Region.

JEL: Q1; Q15

\section{INTRODUÇÃO}

As propostas de ocupação e desenvolvimento, na década de 1970, direcionadas para a Amazônia e o Acre tiveram como motivação principal o crescimento econômico que atendia aos interesses do capital internacional e das

\footnotetext{
${ }^{1}$ Economista. Doutor em Economia Aplicada pela Universidade Estadual de Campinas. Professor da Universidade Federal do Acre

2 Graduando no Curso de Ciências Econômicas na Universidade Federal do Acre.

3 Economista. Doutorando em Desenvolvimento Econômico pela Universidade Estadual de Campinas.
} 
classes dominantes existentes na região e, com isso, muitos destes projetos capitalistas contaram com o amparo do Estado, que por sua vez, representava estes interesses e esteve alheio, em grande parte, à realidade vivenciada no norte do Brasil. Tal como se verificou no caso da exploração do trabalho dos seringueiros, na expulsão de trabalhadores rurais, índios, colonos e na abertura de áreas florestais para implantação de pastagens, o que causou mudanças irreversíveis no modo de vida das populações locais (MARTINELLO, 1985; SILVA, 1990; COSTA FILHO 1995; SOUZA, 2008).

Nos anos de 1900, a população local da Amazônia e do Acre era basicamente formada por índios e caboclos - "os nativos" e, em grande parte, por nordestinos que migravam para a Amazônia em busca de melhores condições de vida ou motivados pelo capital internacional através das políticas de mobilização voltadas para aproveitar a mão-de-obra "farta e barata", aliada às potencialidades daquela região quanto ao desenvolvimento de atividades ligadas ao extrativismo vegetal da borracha. No primeiro ciclo da borracha, entre os anos 1879/1912 e segundo ciclo, entre os anos 1942/1945, o desenvolvimento das atividades extrativistas nos seringais da Amazônia foi pautado pela exploração e opressão na roupagem do "sistema de aviamento", mas com a derrocada do extrativismo vegetal da borracha, ao final da II guerra mundial, em 1947, as propostas de desenvolvimento para a região amazônica passaram a ser pautadas pela mudança na agregação de valor do extrativismo vegetal da borracha para aquelas ligadas à pecuária extensiva (OLIVEIRA, 1982; SILVA, 1990; COSTA FILHO 1995; SOUZA, 2008).

No caso específico do Acre, estes acontecimentos acirraram em todo o Estado, uma série de conflitos sociais pela posse da terra e, em muitos casos, uma forte migração para as cidades, exigindo por parte do poder público, uma ação que amenizasse os impactos socioeconômicos e ambientais, suscitando intensas reações por parte das populações tradicionais que aliadas aos movimentos sociais, contribuíram para a criação das Reservas Extrativistas (RESEX) que se tornaram alternativas não só para a exploração racional dos recursos naturais, como também para atenuar o problema fundiário de concentração de terra (SOUZA, 2010).

Ao avaliar a eficiência econômica da borracha, historicamente o principal produto amazônico, Maciel \& Reydon (2003) expõem que a atividade produtiva é tecnologicamente atrasada e se apresenta com desempenho econômico inferior ao de outras atividades, sendo necessário seu aperfeiçoamento tecnológico sob pena de tornar-se inviável.

Diante dessa realidade de precária geração de renda e possíveis privações, as famílias residentes em áreas de conservação optam por buscar novas oportunidades nas periferias das cidades ou buscam desenvolver atividades ligadas à pecuária, como mecanismo de capitalização ou de poupança, causando a destruição dos recursos naturais (HOMMA, 2008).

É nesse contexto de utilização dos recursos naturais de forma racional e contenção desse público no meio rural para evitar problemas sociais que as RESEX são criadas, que, segundo Brasil (2006), as reservas extrativistas são espaços territorial destinada à exploração autossustentável e conservação dos recursos naturais renováveis, por população tradicionalmente extrativista e o processo de implantação no Brasil ocorreu no início de 1990. O processo de 
regulamentação fundiária da RESEX Chico Mendes iniciou-se em 1992. A Reserva Extrativista foi definida e caracterizada no Art. 18을 Lei 9.985 de 18 de julho de 2000, como:

\footnotetext{
“(...) uma área utilizada por populações extrativistas tradicionais, cuja subsistência baseia-se no extrativismo e, complementarmente, na agricultura de subsistência e na criação de animais de pequeno porte, e tem como objetivos básicos proteger os meios de vida e a cultura dessas populações, e assegurar o uso sustentável dos recursos naturais da unidade" (BRASIL, 2006, p. 8).
}

Para Souza (2010), as RESEX passam então a ser visualizadas por seus idealizadores como uma proposta de desenvolvimento sustentável, principalmente por inaugurar um novo modelo de Unidade de Conservação (UC), que além de admitir a presença do homem, confia a este a corresponsabilidade no monitoramento e fiscalização das florestas.

Nesse processo os produtores extrativistas tornam-se primordiais tanto na produção de produtos extrativistas quanto na conservação ambiental. $E$, entender seus procedimentos produtivos e de reprodução social é fundamental para o fortalecimento das RESEX, visto que os mesmos podem ser enquadrados dentro das características da agricultura.

Assim, a agricultura familiar se caracteriza quando a família é simultaneamente a proprietária dos meios de produção e assume o trabalho nas unidades produtivas. Destarte, todas as técnicas utilizadas na produção são definidas pelos próprios produtores rurais, os quais se utilizam de seus conhecimentos tradicionais em todos os tratos culturais, desde a escolha do local onde será feita a plantação, a maneira como será preparado o solo, as formas de colheita, até o planejamento de como será comercializado o produto final (WANDERLEY, 2003).

A carência de estudos sobre a situação socioeconômica desse segmento na Amazônia, especificamente no estado do Acre, motivou o Projeto de Pesquisa Análise Econômica de Sistemas Básicos da Produção Familiar Rural no Estado do Acre (ASPF), desenvolvido pelo Centro de Ciências Jurídicas e Sociais Aplicadas de Economia da Universidade Federal do Acre (UFAC) a pesquisar, a partir de 1996, os três sistemas de produção predominantes no Estado do Acre, ou seja, extrativista, agrícola e o agroflorestal. O objetivo principal do estudo era de realizar a análise econômica e sociocultural desses sistemas de produção, formular alternativas de desenvolvimento sustentável e disseminar os resultados.

O presente artigo propõe-se a analisar indicadores socioeconômicos dos produtores rurais da RESEX Chico Mendes, baseando-se nos períodos 1996/1997 e 2005/2006, bem como avaliar a situação da produção familiar rural frente ao desempenho econômico, atrelado à pobreza na região, além de comparar a evolução entre os períodos. Destarte, busca-se contribuir nas discussões acerca da pobreza e desigualdade de renda na região, além de subsidiar as políticas públicas para a região de estudo. 


\section{CONCEITUAÇÃO DE POBREZA}

O trabalho de Passos e Nogami (2003) destaca que no caso das Ciências Econômicas, as necessidades humanas são ilimitadas, podem ser econômicas e não econômicas, e para satisfazê-las, é preciso alocar da melhor forma os recursos que em geral possuem a característica de serem limitados ou escassos.

Assim, a satisfação deste conjunto de necessidades tão necessárias à sobrevivência constitui a satisfação das capacidades básicas, as quais são vitais para propiciar as liberdades substantivas dos indivíduos (SEN, 2000). A garantia destas capacidades básicas propicia as liberdades substantivas, que podem ser:

\footnotetext{
"[...] a perspectiva baseada na liberdade apresenta uma semelhança genérica com a preocupação comum com a 'qualidade de vida', a qual também se concentra no modo como as pessoas vivem (talvez até mesmo nas escolhas que têm), e não apenas nos recursos ou na renda de que elas dispõem." (SEN, 2000, p. 39).
}

Entretanto, existe um fenômeno social que é caracterizado por privar o homem do acesso ou condições de satisfação de suas necessidades, trata-se da pobreza. Para Sen (2000), a pobreza deve ser encarada como um elemento de privação destas capacidades e pode repercutir sobre as condições de vida das pessoas, deixando-as em patamares localmente definidos como não desejados.

Segundo Soares (2009) o fenômeno da pobreza pode ter conceitos uni ou multidimensionais. A pobreza unidimensional pode-se relacionar a privações de necessidades básicas devido ao baixo nível de rendimento. Nesta análise há dois parâmetros: Linha de Indigência e Linhas de Pobreza. A primeira se refere ao valor monetário básico para a aquisição de alimentação que contenha a quantidade energética mínima ou recomendada para a sobrevivência. Já, a segunda é um pouco superior à primeira, pois, incluem além da alimentação, todas as outras despesas não alimentares como roupas, educação, moradia, transporte e saúde.

Por outro lado, o aspecto multidimensional da pobreza é considerado as questões fundamentais da sociedade quanto aos direitos e obrigações no exercício da cidadania por meio da análise de variáveis culturais, sociais e políticas (SOARES, 2009). Oliveira (2010) define esse conceito de pobreza em três aspectos distintos: intensidade/severidade, que está relacionada com a mensuração dos níveis de pobreza; tempo/duração, atentando-se com a questão temporal da pobreza, especialmente a sua permanência; e dimensões/ extensões, focando seu estudo nas diversas formas de privação que impedem um indivíduo de possuir uma vida satisfatória.

Paralelo aos problemas ligados a pobreza, os estudos desenvolvidos por Costa (2000) asseveram que a concentração de renda e as desigualdades sociais também são responsáveis por grande parte dos problemas econômicos, sociais e ambientais do Brasil. Aliado a esses problemas, no caso de comunidades rurais da Amazônia, devido a distância e dificuldades de acesso, a baixa participação e/ou inexistência de acesso a serviços sociais básicos tornam as comunidades rurais mais vulneráveis (SOUZA, 2008). 


\section{METODOLOGIA}

\subsection{Tipo Pesquisa, Natureza de Pesquisa e Instrumento de Coleta de Dados}

Esta pesquisa se constitui como uma análise de desempenho econômico, com natureza descritiva e explicativa, o que segundo as definições de Babbie (1999) se baseia em descrever as características, traços e atributos de um determinado grupo social, explicando suas ocorrências. A pesquisa de campo foi realizada com aplicação de questionários com questões abertas e fechadas. Devido às dificuldades de acesso, o levantamento dos dados foi realizado por amostragem, seguindo o critério de que o seringueiro resida na colocação (unidade de produção familiar) há um tempo superior a dois anos. A amostra foi definida a partir de três etapas:

Estratificação da área de acordo com nível de desenvolvimento (alto, médio ou baixo), tendo como referência os critérios relativos aos volumes de produção, facilidade e qualidade de acesso, disponibilidade de infraestrutura e assistência técnica, além do grau de organização comunitária;

- $\quad$ Sorteio de metade dos conglomerados das áreas de estudo - os seringais, no caso de áreas extrativistas, tendo em vista a representatividade dentro de cada estrato definido;

- $\quad$ Por fim, dentro de cada conglomerado sorteado foi realizada uma amostragem aleatória simples, sorteando-se $10 \%$ das unidades de produção, objeto de estudo desta pesquisa.

Para o levantamento das informações socioeconômicas foi considerado o período referente ao ano agrícola trabalhado na região de estudo, discutido de forma amplamente participava dos produtores em questão. Considera-se como ano agrícola o período que se inicia em maio de um ano a abril do ano seguinte. Na RESEX Chico Mendes os períodos levantados foram: 1996/1997 e 2005/2006.

\subsection{Objeto de estudo, localização e acesso}

O presente estudo foi realizado na Reserva Extrativista Chico Mendes, situada na região sudeste do Estado do Acre, criada em 12 de março de 1990, pelo Decreto № 99.114, a região possui cerca de 970.570 ha (hectares), abrangendo os municípios de Rio Branco, Xapuri, Epitaciolândia, Brasiléia, Assis Brasil, Sena Madureira e Capixaba. Por via terrestre o acesso pode ser feito pela rodovia BR 317, que contorna a RESEX em seu lado leste-sul e possui trafegabilidade durante todo o ano. E por via fluvial, através dos Rio Xapuri e seus afluentes, ou pelo Rio laco e Rio Macauã no município de Sena Madureira -exceto em períodos de seca devido o baixo nível das águas (BRASIL, 2006). 


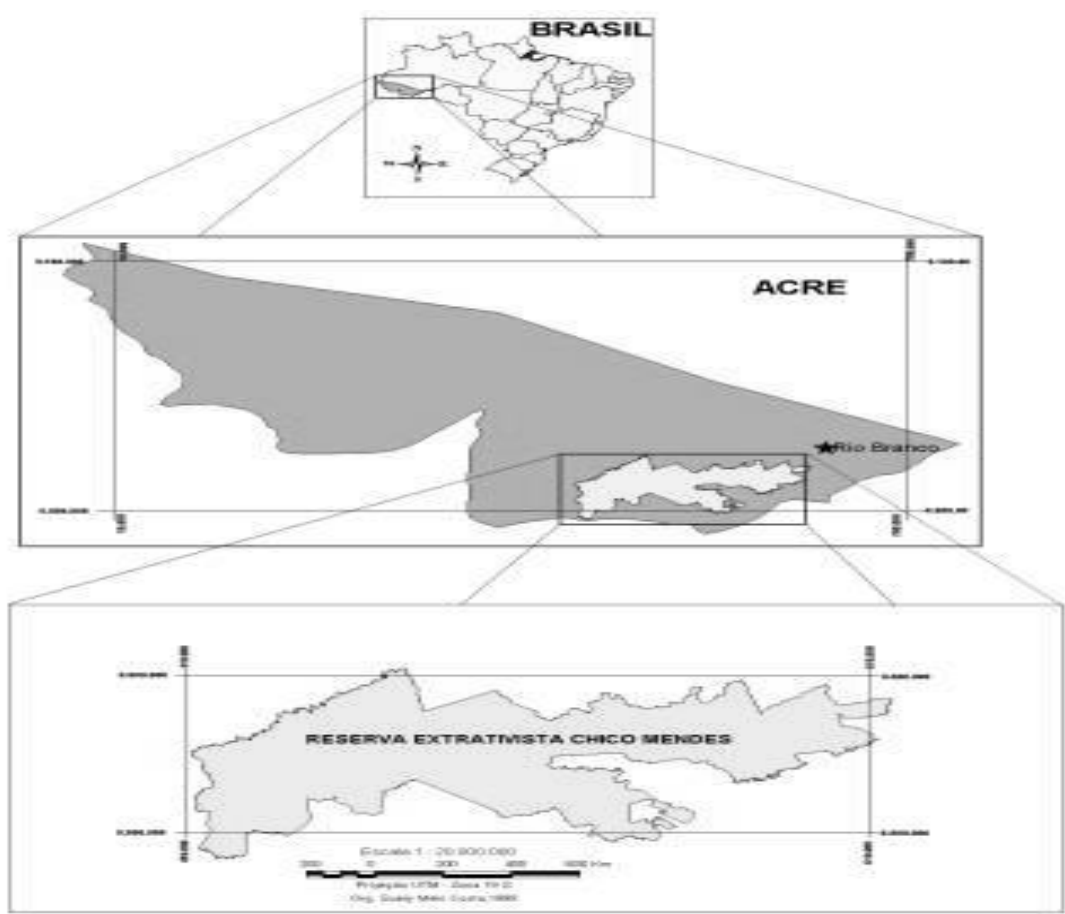

Fonte: Laboratório de Análise e Planejamento Ambiental apud Costa (2008:26).

\subsection{Metodologia de avaliação socioeconômica da RESEX Chico Mendes}

Para fazer a avaliação socioeconômica da produção familiar rural na RESEX Chico Mendes, o presente estudo utilizou a metodologia do Projeto de Análise Socioeconômica dos Sistemas de Produção Familiar Rural no Estado do Acre (ASPF), desenvolvido há mais de 15 anos pelo Departamento de Economia da Universidade Federal do Acre (UFAC), atualmente capitaneado pelo Centro de Ciências Jurídicas e Sociais Aplicadas (CCJSA). Trabalha-se com medidas de resultado econômico, que são indicadores que permitem medir o desempenho econômico dos sistemas de produção estudados. Os principais indicadores econômicos são sucintamente descritos a seguir:

\subsubsection{Resultado Bruto (RB)}

Entende-se por renda bruta ou resultado bruto o valor da produção que se destinará ao mercado.

$$
\mathbf{R B}=\mathbf{Q v} \cdot \mathbf{p p}(\mathbf{1})
$$

Sendo:

$\mathrm{RB}=$ renda bruta

$\mathrm{Qv}=$ quantidade do produto vendida

$\mathrm{pp}=$ preço unitário ao produtor 


\subsubsection{Renda Bruta Total (RBT)}

Somatório da renda Bruta $(\mathrm{RB})$ da produção com a renda oriunda das transferências de renda (bolsa escola, família etc.) e do assalariamento fora da Unidade Produtiva Familiar (UPF). A RBT é calculada para o conjunto da UPF e dos membros da família.

$$
R B T=R B+R T+R A
$$

Sendo:

$\mathrm{RB}=$ renda bruta

$\mathrm{RT}$ = renda das transferências monetárias (municipal, estadual e federal)

$\mathrm{RA}=$ renda de assalariamento fora da UPF

\subsubsection{Margem bruta familiar (MBF)}

É o resultado líquido específico e próprio para indicar o valor monetário disponível para a subsistência da família, inclusive uma eventual elevação do nível de vida, se o montante for suficiente. Em situações favoráveis, poderá ser suficiente para ressarcir custos fixos, especialmente a exigência mínima de reposição do patrimônio. Cumpridas estas funções, a disponibilidade restante pode ser usada como capital de giro. É calculado pela fórmula:

$$
\mathrm{MBF}=\mathrm{RB}-(\mathrm{CV}-\mathbf{C f t f})
$$

Sendo:

$\mathrm{RB}=$ renda bruta

$\mathrm{CV}=$ custos variáveis

$\mathrm{Cftf}=$ custo real da força de trabalho familiar

\subsubsection{Nível de Vida (NV)}

É a totalidade do valor apropriado pelo produtor familiar, inclusive valores imputados, deduzidas as obrigações financeiras com empréstimos. É, portanto, o valor que determina o padrão de vida da família.

$$
\mathbf{N V}=(\mathbf{M B F}+\mathbf{A C}+\mathbf{C j i c c})-\mathbf{A A}
$$

Sendo:

Cjicc = juros imputados ao capital circulante.

$A C=$ Autoconsumo

$\mathrm{AA}=$ Amortização anual 


\subsubsection{Renda Líquida ( $R L)$}

É o valor excedente apropriado pela unidade de produção familiar, ou seja, a parte do valor do produto que fica com a unidade de produção familiar depois de serem repostos os valores dos meios de produção, dos meios de consumo e dos serviços (inclusive salários) prestados à produção. É calculada pela fórmula:

$$
R L=R B-D E
$$

Sendo:

$\mathrm{RB}=$ renda bruta

$\mathrm{DE}$ = despesas efetivas - são todos os valores efetivamente retirados do patrimônio e consumidos de fato no processo de produção. Compreendem os desembolsos monetários para pagar serviços (inclusive pagamento de salários) e/ou adquirir bens consumíveis de gasto imediato (capital circulante de aprovisionamento), o consumo em natureza de bens de gasto imediato, o valor imputado à mão de obra familiar, o valor imputado ao trabalho de administração exercido pelo próprio produtor e a depreciação dos capitais fixos.

\subsubsection{Medidas de Eficiências ou Relação}

a) Índice de eficiência econômica: é a relação que indica a capacidade de a unidade de produção familiar gerar valor por unidade de custo. É um indicador de benefício/custo do conjunto da unidade de produção, definido pela seguinte fórmula:

$$
I E E=\frac{R B}{C T}
$$

Sendo:

$\mathrm{RB}=$ Renda Bruta;

$\mathrm{CT}=$ Custos Totais.

IEE > 1, a situação é de lucro;

IEE $<1$, a situação é de prejuízo;

IEE = 1, a situação é de equilíbrio.

\subsubsection{Linha de dependência do mercado}

A linha de dependência de mercado são os valores medianos gastos com o consumo no mercado, adicionados das compras relacionadas à reposição do 
capital fixo (máquinas, equipamentos, ferramentas, benfeitorias etc.) disponível para a manutenção dos meios de produção existentes.

\subsubsection{Autoconsumo}

Na produção familiar, este índice é de crucial importância na avaliação de desempenho econômico, pois se refere aos valores do que se produz e consome sem necessitar ir ao mercado. O autoconsumo pode ser calculado pela fórmula abaixo:

$$
A C=\sum_{i=1}^{n} Q b c p i * P i
$$

Sendo:

$A C=$ autoconsumo;

Qbcp = quantidade do bem de autoconsumo produzido

$\mathrm{Pi}=$ preço unitário do bem de autoconsumo produzido

$\mathrm{i}=$ itens de bens de autoconsumo produzidos $(i=1,2, \ldots, n)$.

\section{4. Índice de Gini}

O Índice de Gini é uma medida de concentração ou desigualdade utilizada na análise da distribuição de renda e pode ser utilizado para medir o grau de concentração de qualquer distribuição estatística. Assim, essa metodologia analisará essas questões no presente trabalho.

Esse índice funciona da seguinte forma: quanto igual a 0 corresponde a igualdade absoluta e quando igual a 1 corresponde a desigualdade absoluta, assim, quanto mais próximo o índice chegar de 1 pior será a distribuição de renda.

\subsection{Razão $10 \%+$ / 50\%- ou Razão de Kuznets}

Criada por Simon Kuznets (1955), expressa a forma geométrica da relação entre crescimento e desigualdade. Em suma é uma forma de mensurar a desigualdade existente na distribuição de renda dos indivíduos mais ricos com a renda dos indivíduos mais pobres. Compara-se a renda de 10\% dos indivíduos mais ricos relativamente a renda de $50 \%$ dos indivíduos mais pobres. Destaca-se que quanto maior for esta razão maior é a distância das rendas entre os mais ricos e os mais pobres. 


\subsection{Linha de Pobreza}

A maioria dos estudos ligados ao problema da indigência e/ou pobreza definem o valor monetário de $1 / 2$ salário mínimo $(R \$ 362,00)$ e calculam o número de famílias cuja renda é inferior a esta linha. A linha de indigência refere-se à renda mínima necessária para adquirir uma cesta de alimentos com quantidades energéticas mínimas ou recomendadas. A linha de pobreza é superior à linha de indigência, pois incluem, além do valor da cesta de alimentos, todas as outras despesas não alimentares, como vestuário, moradia, transportes etc. (CAMPOS \& CAMPOS, 2008).

Entre os métodos que definem a linha de indigência ou pobreza definida pela renda destacam-se aqueles que se utilizam da proporção do salário mínimo. Este método é bastante utilizado, pois em tese, o salário mínimo deveria suprir as necessidades básicas, não só da alimentação, mas também da moradia, vestuário etc. Os valores comumente utilizados como linha de pobreza são de 1/4 ou $1 \frac{1}{2}$ do salário mínimo.

De acordo com o levantamento de dados realizado pelo projeto ASPF realizado entre os anos de 1996/1997 a 2005/2006, a renda dos produtores das UPF's da RESEX Chico Mendes foram divididas em cinco classes sociais de acordo com o salário mínimo nacional, sendo a classe A composta por produtores que detém uma renda acima de quatro salários mínimos, a classe $B$ de dois a quatro salários mínimos, a classe $C$ de $1 / 2$ a dois salários mínimos, a classe $D$ que ganham até $1 / 2$ salário mínimo e pôr fim a classe $E$, famílias com renda inferior a 1/4 de salário mínimo.

\subsection{Atualização Monetária}

Para realizar a atualização de preços utilizou-se o Índice Nacional de Preços ao Consumidor (INPC), elaborado pelo Instituto Brasileiro de Geografia e Estatística (IBGE). Assim, foram coletados os valores correntes (em reais) nos períodos de 1996/1997 e 2005/2006, atualizando os valores até setembro de 2014.

\section{RESULTADOS E DISCUSSÕES}

\subsection{Avaliação do Desempenho Econômico das Famílias da RESEX Chico Mendes}

Conforme a Tabela 1, no período em torno de uma década (1996/1997 a 2005/2006), houve uma reversão na geração de renda bruta de acordo com as atividades produtivas desempenhadas pelas famílias da RESEX Chico Mendes, uma vez que as atividades de criações de animais e agrícolas, que tinham maior participação na composição da renda bruta das famílias no primeiro período apresentaram redução em relação às atividades extrativistas. 
Tabela 1 - Participação dos produtos na composição da Renda Bruta, (1996/1997 a 2005/2006).

\begin{tabular}{lccc}
\hline \multirow{2}{*}{ Descrição } & \multicolumn{3}{c}{ Renda Bruta } \\
\cline { 2 - 4 } & $\mathbf{1 9 9 6 / 1 9 9 7}$ & $\mathbf{2 0 0 5 / 2 0 0 6}$ & Variação \\
\hline Linha de exploração & $\%$ & $\%$ & $\%$ \\
Agricultura & $\mathbf{3 4 , 1}$ & $\mathbf{2 4 , 7}$ & $\mathbf{- 2 7 , 5}$ \\
Macaxeira & 10,3 & 10,6 & 2,4 \\
Arroz & 7,3 & 7,3 & $-0,4$ \\
Feijão & 6,8 & 1,8 & $-73,7$ \\
Melancia & 6,6 & 1,0 & $-85,4$ \\
Milho & 1,9 & 1,0 & $-45,0$ \\
Outros & 1,2 & 3,1 & 150,1 \\
Criações & $\mathbf{3 7 , 3}$ & $\mathbf{3 0 , 2}$ & $\mathbf{- 1 9 , 1}$ \\
Criação de bois/leite/queijo & 11,1 & 17,5 & 57,1 \\
Criação de porcos & 11,0 & 6,0 & $-45,3$ \\
Criação de aves/ovos & 12,0 & 5,2 & $-56,5$ \\
Criação de ovelhas & 1,8 & 0,8 & $-55,8$ \\
Outros & 1,4 & 0,7 & $-52,0$ \\
Extrativismo & $\mathbf{2 8 , 6}$ & $\mathbf{4 5 , 1}$ & $\mathbf{5 7 , 7}$ \\
Castanha & 15,2 & 27,1 & 78,2 \\
Borracha & 13,4 & 9,5 & $-29,1$ \\
Castanha certificada & - & 4,3 & - \\
Madeira & - & 4,2 & - \\
Total & $\mathbf{1 0 0 , 0}$ & $\mathbf{1 0 0 , 0}$ & - \\
\hline
\end{tabular}

Fonte: Projeto ASPF (2014).

No caso da produção agrícola, tal redução justifica-se pelas dificuldades de escoamento, aumento dos custos de produção e pelo emprego de baixo nível tecnológico. No que se refere às criações, verifica-se uma redução na participação da renda bruta total, examinando o percentual geral da categoria. No entanto, ao observar especificamente essa participação, percebe-se que esta redução ocorreu apenas para as criações de menor importância comercial (porcos, aves e ovelhas), utilizadas essencialmente como complemento de renda e autoconsumo, em virtude das mesmas dificuldades apresentadas para os produtos agrícolas.

Todavia, a participação da criação de bois na composição da renda bruta total aumentou $57,1 \%$, decorrente das vantagens no transporte para o mercado consumidor, como também da grande demanda e preço de mercado garantido. Mesmo assim, a categoria criações, de forma genérica, teve uma participação menor na composição da renda bruta, uma vez que o aumento da participação da criação de bois, embora muito significativo, não foi superior a redução da participação das criações de menor porte. A partir destas informações percebe-se uma migração na agregação de renda da atividade de criação de animais de pequeno porte para a criação de bois e também uma forte migração para as atividades extrativistas. Isso evidencia a constante concorrência entre atividades ambientalmente sustentáveis e não sustentáveis, notadamente do ponto de vista ambiental, as quais necessitam ser praticadas de forma extensiva para garantir uma produção rentável, resumindo-se em contínuo desflorestamento (MACIEL, 
MACHADO, CAVALCANTE FILHO, 2013). Mas, tal migração está fortemente associada à criação da própria RESEX, na qual uma das finalidades iniciais era justamente o fortalecimento das atividades extrativistas.

O acentuado crescimento da participação de atividades extrativas na composição total da renda bruta ocorreu, essencialmente, em virtude dos incentivos prestados ao setor extrativista, por meio de programas governamentais de apoio à produção de borracha e castanha-do-brasil, como também, posteriormente ao período analisado, a instalação da fábrica de preservativos masculinos em abril de 2008, no município de Xapuri - AC. Ademais, vale ressaltar que, dos produtos extrativistas, o que apresentou maior crescimento na participação da renda foi a castanha-do-brasil, considerada por grande parte dos seringueiros como principal atividade econômica das famílias, tendo em vista o bom preço de mercado que tem alcançado nos últimos anos. Além disso, a maior organização na cadeia produtiva e a garantia de mercado tem proporcionado maior segurança aos extrativistas de castanha-do-brasil.

A Tabela 2 apresenta o desempenho econômico da produção na RESEX Chico Mendes. A pesquisa evidenciou que no período de 1996/1997 o valor da Renda Bruta (RB) com a produção foi de $R \$ 432,06$, passando para $R \$ 560,79$ em 2005/2006. Neste período, houve uma variação positiva em 29,79\%. A Renda Líquida (RL) teve uma variação positiva em $40,84 \%$, esta vantagem apresentada no último período ocorreu principalmente pelo aumento de representatividade dos produtos extrativistas na composição da renda familiar, principal fonte de produção no interior da RESEX, o qual utiliza baixo nível tecnológico em sua exploração. Tal desempenho também incidiu sobre os resultados apresentados na Margem Bruta Familiar (MBF), a qual apresentou uma variação positiva em $33,85 \%$, o que tornou possível o aumento no potencial de consumo da família. Entretanto, mesmo com esta elevação na renda com a produção, observou-se que esses indicadores apresentam valores medianos inferiores ao salário mínimo vigente $(R \$ 724,00)$.

Assim, na busca por rendimentos extras ao processo produtivo, as famílias extrativistas recorrem ao assalariamento fora da unidade produtiva e, principalmente, aos benefícios governamentais concedidos em forma de transferências de rendas, como o Programa Bolsa Família e as aposentadorias. De acordo com a tabela 2, Renda Bruta Total expressa bem o papel das rendas extras atuais, em particular os benefícios governamentais, uma vez que no período de 2005/2006 o valor recebido pelas famílias, somando a renda bruta com as extras, praticamente iguala o valor do salário mínimo mensal vigente, o que garante maior acesso à satisfação das necessidades da família no mercado.

$\mathrm{O}$ autoconsumo (AC) representa monetariamente o quanto da produção que é consumido e não pago. Esse indicador teve uma redução em $54,01 \%$ no período analisado. Isso significa que as famílias residentes na RESEX Chico Mendes estão produzindo menos produtos para sua subsistência. Com a redução do AC, é natural que as famílias substituam seus itens de consumo por produtos industrializados e, este indicador é a Linha de Dependência do Mercado (LDM), a qual teve um significativo aumento, passando de $R \$ 389,86$ em 1996/1997 para $\mathrm{R} \$ 1.227,80$ em nove anos, ou seja, as UPF's ficaram mais dependentes do mercado em $214,93 \%$, fato preocupante no meio rural, uma vez que o autoconsumo é uma das principais fortalezas da produção familiar rural e seu 
enfraquecimento retrata maior tendência de endividamento externo dado 0 aumento da LDM muito superior a Renda Bruta (RB).

\begin{tabular}{|c|c|c|c|c|}
\hline Indicadores Econômicos & Unidade & 1996/1997 & 2005/2006 & $\begin{array}{c}\text { Variação } \\
\text { (\%) }\end{array}$ \\
\hline Renda Bruta & $\mathrm{R} \$ / \mathrm{mês}$ & 432,06 & 560,79 & 29,79 \\
\hline Renda Líquida & $\mathrm{R} \$ / \mathrm{mês}$ & 303,79 & 427,85 & 40,84 \\
\hline Margem Bruta Familiar & $\mathrm{R} \$ / \mathrm{mês}$ & 384,48 & 514,65 & 33,85 \\
\hline Renda Bruta Total & $\mathrm{R} \$ /$ mês & 396,42 & 706,63 & 78,25 \\
\hline Linha de Dependência do Mercado & $\mathrm{R} \$ / \mathrm{mês}$ & 389,86 & $1.227,80$ & 214,93 \\
\hline Autoconsumo & $\mathrm{R} \$ /$ mês & $1.315,26$ & 604,94 & $-54,01$ \\
\hline Nível de Vida & $\mathrm{R} \$ / \mathrm{mês}$ & $1.721,56$ & $1.226,67$ & $-28,75$ \\
\hline Índice de Eficiência Econômica & und. & 1,36 & 0,7 & $-48,52$ \\
\hline
\end{tabular}

Obs: Resultados medianos por Unidade de Produção Familiar (UPF). Atualização monetária até setembro de 2014 (INPC/IBGE).

Fonte: Projeto ASPF (2014).

Ter dificuldade em gerar renda com as atividades produtivas e apresentar elevações significativas na LDM são fatores que afetam diretamente no Nível de Vida (NV), em termos monetários, das famílias da RESEX Chico Mendes. Neste estudo, o NV teve uma variação negativa de $28,75 \%$, o que evidencia uma diminuição representativa nos rendimentos monetários apropriados pelo produtor. Estes dados são reforçados pelo Índice de Eficiência Econômica (IEE), o qual mostra a relação custo/benefício das atividades produtivas. O que se percebeu foi uma queda de eficiência em 48,52\%, ou seja, de forma mediana as unidades produtivas apresentaram situação de prejuízo.

Apesar da queda no NV e do IEE no período de 2005/2006, ressalta-se que ainda é vantajoso para o produtor continuar na RESEX, pois, em termos monetários, o NV ficou próximo de dois salários mínimos mensais vigentes, rendimento que dificilmente seria obtido nas periferias das cidades, onde 0 mercado de trabalho é caracterizado por uma concorrência bem acirrada, cujas oportunidades estão distantes das qualificações dos extrativistas.

\subsection{Avaliação da evolução dos indicadores de distribuição de renda e pobreza na RESEX Chico Mendes}

De acordo com a tabela 3, observa-se, por um lado, que o Índice de Gini evidencia uma diminuição de $8,16 \%$ da concentração de renda entre os extrativistas da RESEX Chico Mendes, no período em torno de uma década (1996/1997 a 2005/2006). Destaca-se, ainda, a redução de 36\% da apropriação da renda total pelos $10 \%$ mais ricos, que, de forma agregada, levou a diminuição em $56 \%$ na razão de apropriação de renda entre os mais ricos e os mais pobres.

Essa redução é explicada pelo fortalecimento da geração de renda por intermédio das atividades extrativistas, como demonstrado na tabela 1 , resultado de políticas públicas efetivas, como a Lei Chico Mendes e a organização do 
arranjo produtivo da castanha-do-Brasil. Portanto, o efetivo desenvolvimento sustentável para as áreas florestais passa, necessariamente, pelo revigoramento das atividades extrativistas da região.

Por outro lado, a tabela 3 demonstra, também, um considerável nível de concentração de renda, no período recente (2005/2006), com o índice de Gini em torno de 0,45 .

Destaca-se que o percentil de produtores entre os $10 \%$ mais ricos se apropriaram de $16 \%$ do total da renda bruta gerada. Uma das possíveis explicações para essa persistência está no aumento em torno de $57 \%$ - similar ao percentual de aumento do extrativismo - na criação de gado bovino (ver tabela 1), especialmente por uma atividade concentradora de renda, dadas suas características produtivas essencialmente extensivas, além, claro, das necessidades de seu nível de capitalização.

\begin{tabular}{|c|c|c|c|}
\hline Indicadores & $1996 / 1997$ & $2005 / 2006$ & Variação \\
\hline $\begin{array}{l}\text { ÍNDICE DE GINI } \\
\text { RAZÃO DE KUZNETS }\end{array}$ & 0,49 & 0,45 & $-8,16 \%$ \\
\hline$\%$ renda $10 \%+$ & $25 \%$ & $16 \%$ & $-36,00 \%$ \\
\hline$\%$ renda $50 \%-$ & $25 \%$ & $31 \%$ & $24,00 \%$ \\
\hline Razão entre $10 \%+/ 50 \%-$ & 1 & 0,51 & $-56,03 \%$ \\
\hline
\end{tabular}

Agora, pode-se visualizar melhor a distribuição de renda na RESEX Chico Mendes a partir dos estratos de renda - tendo como referência o Nível de Vida (NV) das famílias -, enfocando as discussões sobre a pobreza na região de estudo.

Um primeiro aspecto a ser ressaltado, conforme a Figura 3, refere-se à constatação de que não havia nenhuma família produtora enquadrada na Classe $\mathrm{E}$, em ambos os períodos pesquisados, ou seja, não existia e nem existem miseráveis na RESEX Chico Mendes. Um ponto a ser destacado quando se compara com as periferias das cidades, frequentes abrigos dos miseráveis urbanos.

Na Classe D, composta por famílias consideradas pobres, de acordo com a linha de pobreza considerada no presente estudo, percebe-se uma expressiva redução em torno dos $68 \%$, no período em torno de uma década, sendo que apenas $6 \%$ das famílias da região foram consideradas pobres, no período recente (2005/2006). Essa redução pode ser creditada, de forma geral, ao fortalecimento das atividades extrativas, que estão disponíveis a todas as classes de renda, segundo demonstrado na tabela 1. 
Figura 3 - Estratificação das famílias da RESEX Chico Mendes, por rendimentos (Nível de Vida), de acordo com a linha de pobreza, 1996/1997 2005/2006.

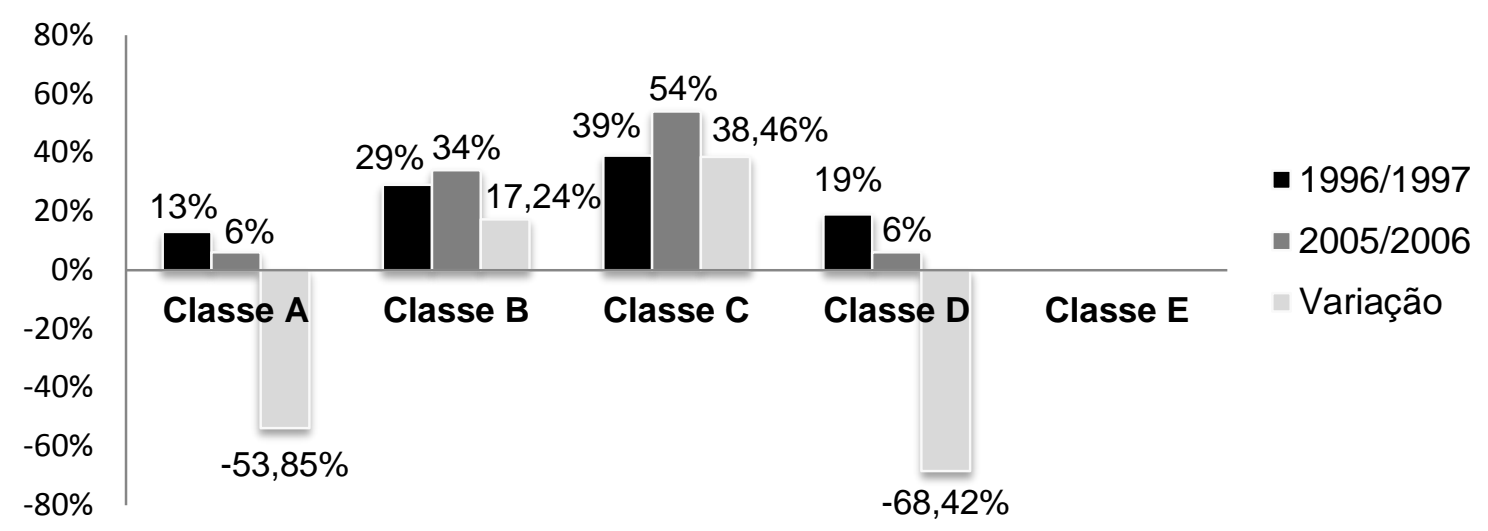

Fonte: Projeto ASPF (2014).

No outro extremo da estratificação, na Classe A, de maior renda, composta por famílias com NV superiores a quatro salários mínimos mensais, percebe-se o mesmo movimento da Classe pobre (D), ou seja, uma significativa redução $(53,85 \%)$ das famílias nesse estrato, identificando-se apenas 6\% destas. Esse resultado indica as dificuldades de geração de renda no sistema e, por conseguinte de autoconsumo, além de uma melhora na distribuição dos baixos rendimentos.

Tais rendimentos levaram à classificação de $54 \%$ dos produtores na Classe C, cujas famílias têm NV entre meio a dois salários mínimos mensais, no período de 2005/2006, expressando os rendimentos medianos do sistema.

Assim, os resultados encontrados para o índice de Gini, que permite avaliar os efeitos das políticas públicas sobre a distribuição da riqueza, bem como da distribuição da população por estratos de rendimento, tendo em vista a linha de pobreza, apresentam um sútil avanço na questão de distribuição de renda e leve atenuação da pobreza, além de evidenciar a necessidade de condução a novas políticas que busquem, por um lado, a erradicação da pobreza e, por outro, a elevação do nível de vida das populações florestais, como é o caso dos moradores da RESEX Chico Mendes.

Nesse sentido, o aprofundamento das pesquisas torna-se primordial na busca de alternativas produtivas sustentáveis, especialmente extrativistas, que podem efetivamente encaminhar o processo de desenvolvimento da região.

\section{CONSIDERAÇÕES FINAIS}

A análise comparativa de dois ciclos produtivos na Reserva Extrativista Chico Mentes permitiu conhecer as mudanças ocorridas na região, no que diz respeito aos aspectos de produção, pobreza e desigualdade de renda, em um espaço de tempo de aproximadamente dez anos. 
Portanto, este estudo objetivou identificar o desempenho econômico e a distribuição de renda como forma de combate a pobreza rural na Reserva Extrativista Chico Mendes nos períodos de 1996/1997 e 2005/2006.

Dentre os principais resultados, destaca-se o crescimento da participação das atividades extrativistas na composição da renda e os incentivos para a produção e comercialização de tais produtos, o que elevou o rendimento médio das famílias.

Entretanto, mesmo com essa elevação nos rendimentos percebeu-se que, na média das famílias, estão inferiores ao salário mínimo vigente $(R \$ 724,00)$ e, paralelo a este processo, houve uma diminuição do autoconsumo, conjugado com a elevação do montante de consumo no mercado, o que por sua vez, diminui o valor apropriado pelas famílias, essencial para a melhoria do nível de vida.

Tal cenário acena para a formulação de políticas públicas específicas e voltadas para o incentivo e fortalecimento da produção e renda rural através do acesso a tecnologias e exploração sustentáveis dos recursos naturais de modo a garantir a satisfação das necessidades básicas.

A análise do Índice de Gini evidenciou que houve redução na desigualdade. E o desempenho entre as classes permitiu observar que na passagem do primeiro para o segundo, houve acentuada migração das famílias contidas nas classes A e D para as classes B e C. Isso representa uma diminuição da pobreza com o simultâneo indício de distribuição de renda das famílias que residem na região.

A presente pesquisa identificou um pequeno avanço em relação à distribuição de renda e pobreza entre as famílias que residem na Reserva Extrativista Chico Mendes, mediante as políticas de fortalecimento da produção extrativista, principalmente à castanha e borracha, bem como a implantação de uma agroindústria de preservativos masculinos, a qual tem como sua principal matéria-prima o látex, viabilizando a cooperativa de produtores da região.

O trabalho apresenta algumas limitações referentes aos períodos trabalhados. Dessa forma, sugere-se que novas pesquisas sejam realizadas para verificar o avanço de políticas implementadas na região, bem como identificar a situação atual das famílias.

\section{REFERÊNCIAS BIBLIOGRÁFICAS}

ASPF - Análise Socioeconômica de Sistemas Básicos de Produção Familiar Rural no Estado Acre. 2014. Disponível em: <http://aspf.wordpress.com>. (Projeto de Pesquisa do Centro de Ciências Jurídicas e Sociais Aplicadas da UFAC). 2014.

BABBIE, Earl. Métodos de pesquisa de survey. Belo Horizonte: Ed. UFMG, 1999. 519 p.

BRASIL. Ministério do Meio Ambiente. Plano de Manejo: Reserva Extrativista Chico Mendes. Xapuri - AC, 2006. 91 p.

CAMPOS, Roberio T. \& CAMPOS, Kilmer C. Análise das medidas de renda, distribuição e pobreza dos Municípios da área de influência da Barragem 
Castanhão Ceará. Rio Branco: 46ำ Congresso da Sociedade Brasileira de Economia, Administração e Sociologia Rural (SOBER) Julho 20-23, 2008.

CEARÁ (Estado). Governo do Estado do Ceará. O Índice de Gini como medida de concentração de renda. Fortaleza: Secretaria do Planejamento e Coordenação (SEPLAN), 2006.

COSTA, Jeísa Acióle da. Pagamento pelos serviços ambientais na Reserva Extrativista Chico Mendes. Monografia para obtenção do título bacharel em Economia, Universidade Federal do Acre, UFAC, 2008. 55p.

COSTA, Suely de Souza Melo da. Caracterização Ambiental da Reserva Extrativista Chico Mendes (Acre-Brasil): Subsídios ao Plano de Manejo. Florianópolis: UFSC, 2000. Tese (Doutorado em Ciências).

HOMMA, Alfredo K. O. Expansão agropecuária e desmatamento na Amazônia: quais os caminhos? In: COELHO, Alexandre. B. et. al (org) naturais e crescimento econômico. Viçosa. 2008. p. 125-176.

KUZNETS, S. 1955. Economic Growth and Income Inequality. American Economic Review, v.45, n.1.

MACIEL, Raimundo C. G.; MACHADO, Emerson L. C.; CAVALCANTE FILHO, Pedro G. Avicultura versus Gado Bovino no Acre: Agricultura Familiar e Desenvolvimento Rural em Questão. In: ENCONTRO DA SOCIEDADE BRASILEIRA DE ECONOMIA ECOLÓGIA, 10. 2013. Anais. Vitória: 2013.

; REYDON, Bastiaan P. Ilhas de Alta Produtividade: inovação no ambiente amazônico. In: Congresso Brasileiro de Economia e Sociologia Rural, XLI., 2003, Juiz de Fora. Anais... Juiz de Fora: SOBER, 2003. 18 p. (1 CDROM). $103 \mathrm{p}$.

MARTINELLO, Pedro. A "batalha da borracha" na segunda guerra mundial e suas consequências para o vale amazônico. 1985. 368p. Tese (Doutorado em História Econômica) - USP, São Paulo, 1985.

OLIVEIRA, Leonardo Santos de. Três Ensaios sobre Pobreza Multidimensional. Rio de Janeiro, 2010. 123 p. Teses (Doutorado em Economia) - Programa de Doutorado em Economia, Universidade Federal do Rio de Janeiro, Rio de Janeiro. 2010.

OLIVEIRA, Luiz Antônio Pinto de. O sertanejo, o brabo e o posseiro: a periferia de Rio Branco e os cem anos de andança da população acreana. Belo Horizonte: UFMG, 1982, 145p. Tese (Mestrado em Economia) CEDEPLAR/UFMG, Belo Horizonte.

PASSOS, Carlos Roberto Martins \& NOGAMI, Otto. Princípios de economia. São Paulo: Pioneira Thomson Learning, 2003. p. 1- 23.

SEN, A. Desenvolvimento como liberdade. São Paulo: Companhia das Letras, 2000. p. 1 - 219.

SILVA, Adalberto Ferreira da. Raízes da ocupação recente das terras do acre: movimento de capitais, especulação fundiária e disputa pela terra. Rio Branco: Casa da Amazônia, 1990, 79 p. Dissertação (Mestrado em Economia Regional) - CEDEPLAR/Universidade Federal de Minas Gerais (UFMG), Belo Horizonte. 1990. 
SOARES, Sergei Suarez Dillon. Metodologias para estabelecer a linha de pobreza: objetivas, subjetivas, relativas, multidimensionais. Rio de Janeiro, 2009, 50p.

SOUZA, Elyson F. Os polos agroflorestais como política de desenvolvimento rural sustentável em Rio Branco no Acre: da proposição à realidade. Viçosa: Departamento de Economia Doméstica/UFV, 2008. 187 p. (Mestrado em Economia Doméstica).

SOUZA, Gisele Elaine de A. Batista. Reserva Extrativista Chico Mendes - AC: os desafios de gestão (com)partilhada. Viçosa: Departamento de Economia Rural/UFV, 2010. 218 p. (Mestrado em Extensão Rural).

WANDERLEY, M. de N. B., Agricultura familiar e campesinato: rupturas e continuidade, Estudos Sociedade e Agricultura, Rio de Janeiro, n. 21, p. 42-61, out. 2003. 